\title{
Smoking is associated with osteoporosis development in Primary care population
}

\author{
Kleisiaris F. Christos ${ }^{1, ~}$, Plaiti E. Maria ${ }^{1}$, Papathanasiou V. Ioanna ${ }^{2}$, Papaioannou Polina ${ }^{1}$, \\ Kastrinakis Ioannis ${ }^{1}$, Diakantoni Sofia ${ }^{1}$, Fradelos Evangelos ${ }^{3}$, Kourkouta Lamprini ${ }^{4}$ \\ ${ }^{1}$ Department of Nursing, Technological Institute of Crete, Heraklio, Greece \\ ${ }^{2}$ Department of Nursing, Technological Institute of Thessaly, Larisa, Greece \\ ${ }^{3} 3^{\text {rd }}$ Psychiatric Department, State Mental Hospital of Attica "Daphne", Athens, Greece \\ ${ }^{4}$ Department of Nursing, Technological Institute of Thessaloniki, Thessaloniki, Greece
}

\section{Email addresss:}

chrisklisiaris@staff.teicrete.gr (Kleisiaris F. C.), maria-plaiti@hotmail.com (Plaiti E. M.), papathan@teilar.gr (Papathanasiou V. I.), pwlina18@hotmail.com (Papaioannou P.), katsrinakisg@hotmail.com (Kastrinakis I.), evagelosfradelos@hotmail.com(Fradelos E.), lkourkouta@nurse.teithe.gr (Kourkouta L.)

\section{To cite this article:}

Kleisiaris F. Christos, Plaiti E. Maria, Papathanasiou V. Ioanna, Papaioannou Polina, Kastrinakis Ioannis, Diakantoni Sofia, Fradelos Evangelos, Kourkouta Lamprini. Smoking is Associated with Osteoporosis Development in Primary Care Population. American Journal of Nursing Science. Special Issue: Mental Health Care: Aspects, Challenges and Perspectives. Vol. 4, No. 2-1, 2015, pp. 96-101. doi: 10.11648/j.ajns.s.2015040201.28

\begin{abstract}
Introduction: Osteoporosis is a disease of bones and it has been associated with various risk factors such as female gender, advanced age and smoking habit. However, evidence has shown that the true figures between osteoporosis and smoking are conflicted. Aim: This study was aimed to screen individuals for potential risk factors related to osteoporosis and to assess whether smoking habit is associated with osteoporosis development in Primary care population aged 45 years and over. Materials and Methods: A screening program for osteoporosis was conducted in two Primary care settings in the island of Crete - Greece, during a 3-month period (April to June 2013). We studied 400 participants aged 45 years old and over for riskfactors associated with osteoporosis development using the ONE Minute Osteoporosis Risk Test. Participants were screened for to 19 risk-factors related to osteoporosis such as fracture, diagnosis of Thyroid, Alcohol Consumption and smoking responding to Yes or No. Statistically, chi square and/or Variance analysis were used for the descriptive characteristics of the study participants and the significance of association among demographic characteristics. The method of variance analysis was applied to determine associations between risk factors and demographic characteristics. Bivariate associations were described using Odds Ratio (OR) with $95 \%$ Confidence Intervals (CI). P-values $\leq 0.05$ was considered significant using the SPSS version 21.0. Results: The mean age of participants $(50 \%$ males) was $61.94 \pm 11.6$. Males were smoked significantly more often $(75.5 \%$ vs. $43 \%, \mathrm{p}<0.001)$ than females and, current smokers both females $(\mathrm{OR}=1.12 ; 95 \% \mathrm{CI}: 0.25-1.99, \mathrm{p}=0.012)$ and, males $(\mathrm{OR}=0.85$; $95 \% \mathrm{CI}: 0.10-1.59, \mathrm{p}=0.027)$ were significantly more likely to report an increased number of risk-factors for osteoporosis compared to never smokers. We also found that obese participants were less likely to report an increased number of risk-factors $(\mathrm{OR}=-1.87 ; 95 \% \mathrm{CI}$ : $-3.54,-0.20, \mathrm{p}=0.029)$ compared to reference category suggesting that obesity was a protective factor for osteoporosis, but this association was significant only for males. Conclusion: Although a number of riskfactors did not differ among non-smokers, former and current smokers, current smokers had a greater likelihood of reporting a number of risk-factors related to osteoporosis, suggesting that smoking is an important risk factor for osteoporosis development.
\end{abstract}

Keywords: Osteoporosis, Female Gender, Age, Smoking, Bone Fracture

\section{Introduction}

Osteoporosis is the most common systemic skeleton illness that characterized by reduce of bone mass and disruption of bone architecture resulting an increased risk of fragility fractures which represent the main clinical consequence of the disease. It is often called the silent disease because the loss of bone occurs silently and progressively and there are 
no symptoms until the first fracture occurs [1]. Worldwide, osteoporosis is considered a global public health problem currently affecting over than 200 million people [2]. In particular, 1 in 3 women over 50 years old will experience osteoporotic fractures in contrast with 1 in 5 men [3]. Evidently, the overall prevalence of osteoporosis is higher in females approaching 80\% [4], morbidity and mortality for osteoporotic fractures was found higher in males, even though the mean age of fractures appearance was about 5-10 years later than females [5].

In the international literature, factors such as age, female gender and/or rheumatoid arthritis mental have been evaluated as risk-factors for osteoporosis development due to having lower bone density, presenting a twice probability to experience mortality [6, 7]. Mental disorders have also a negative impact on bone health with most common depression and eating disorders (anorexia nervosa) in accordance with the National Osteoporosis Foundation statement [8]. In addition, the World Health Organization (WHO) recommended that females are much more likely to develop osteoporosis that gradually increased with age [9]. Furthermore, low dietary calcium and lifestyle (smoking and alcohol consumption) have also been associated for an increased risk for osteoporosis, especially tobacco use as recently reported for the Greek citizens with $40 \%$ proportion $[10,11]$. Therefore, due to the fact that Greek population was classified in the first position for smoking among European countries, we consider that smoking might be related to an increased risk for osteoporosis development, especially in primary care population.

Subsequently, this study was aimed to investigate the frequency of factors related to a risk for osteoporosis and to evaluate whether smoking habit is associated with an increased risk for Osteoporosis in Primary care population aged 45 years and over. Our secondary aim was to explore possible differences between males and females.

\section{Materials and Methods}

\subsection{Study Design}

In this cross-sectional study we carried out a pre-screening test for Osteoporosis in two Primary care settings during a 3month period (April to June 2013) in the island of Crete Greece. We enrolled patients who visited the specific settings for any reason and were willing to be involved after the oral briefing by researchers for the procedures of the study. Critically, patients with previous diagnosis for osteoporosis and aged less than 45 years were excluded from the study. Finally, 470 self-administrative questionnaires were distributed and, a total of 400 questionnaires were fully completed and included in the statistical analysis - (response rate of $85.1 \%$ ).

\subsection{Study Instrument}

The Greek version of the One Minute Osteoporosis Risk Test was used to access risk-factors for osteoporosis.
Originally, it is a self-assessment test by the International Osteoporosis Foundation (IOF) and it has been widely used for a short screening health status bones and the potential risk of fracture [12]. It is consisted of 19 questions and was divided into modifiable (5 questions) and non modifiable (14 questions) risk factors taking into consideration gender, family history, personal clinical and lifestyle factors. From the total of 19 questions, 18 are concerned females and 16 questions males, based on participants responses (Yes/No). More positive answers "yes" to these questions it does not necessarily mean that a person has or develop Osteoporosis, it is however indicative for seeking medical advice.

Smokers were defined as tobacco users of $\geq 30$ packs per year $(20$ cigarettes/pack $)$ following the WHO recommendations. As far concerning the estimation of risk factors, alcohol consumption was evaluated as a unit of alcohol which is equivalent to $10 \mathrm{ml}$ (or approximately 8 grams) of pure ethanol. Especially, the active chemical ingredient in alcoholic beverages, one unit of beer or cider $(4 \%$ alcohol) is $250 \mathrm{ml} / 8.75 \mathrm{oz}$., one unit of wine ( $12.5 \%$ alcohol) is $80 \mathrm{ml} / 2.80 \mathrm{oz}$., and one unit of spirits ( $40 \%$ alcohol) is 25 $\mathrm{ml} / 0.88$ oz. [12]. Body Mass Index (BMI) was also assessed and expressed as fraction $\left(\mathrm{kg} / \mathrm{m}^{2}\right)$ into 4 categories as follows; a BMI less than 18.5 indicates underweight (reference category), a BMI 18.5 - 24.9 indicates Normal, while a BMI greater than 25 is considered Overweight and above 30 indicates Obese according to the World Health Organization [13].

\subsection{Ethics}

The study was approved by the Scientific Council of Nursing Department of Technological Institute of Crete as a part of nursing intervention in Primary care population. Completing the questionnaire, all the participants gave informed consent while underlining that their participation was voluntary.

\subsection{Statistical Analysis}

The descriptive characteristics of the study participants were controlled for the significant of differences using $\mathrm{x}^{2}$ and Student $t$ test were appropriate. Additionally, variance analysis was applied to determine associations between risk factors and demographic characteristics. Logistic regression was also applied to evaluate the likelihood of reporting riskfactors to the number of risk-factors (Mean Value) among genders and presented as odds ratio (OR) with 95\% corresponding Interval consistency $(\mathrm{CI})$. All reported Pvalues were two-tailed, and P-values $\leq 0.05$ was considered statistically significant using the SPSS version 21.0.

\section{Results}

Demographic characteristics of the study participants were presented in Table 1. The mean age of our sample was $61.94 \pm 11.6$ years old, and was significantly greater for males than females $(63.91 \pm 11.9$ vs. $59.96 \pm 11.2, \quad \mathrm{p}=0.001)$, 
respectively. Underweight and normal BMI (18.5\% and 59\%, $\mathrm{p}=0.001)$ for males and was greater in comparison to $(10 \%$ and $52 \%)$ of females. However, males were presented more overweight $(34 \%$ vs. $18 \%, \mathrm{p}=0.001)$ and, were smoked significantly more frequent $(36.5 \%$ vs. $21.5 \%, \mathrm{p}<0.001)$ than females.

Table 1. Patients' characteristics

\begin{tabular}{llll}
\hline Demographic characteristics & Male $(\mathbf{n}=\mathbf{2 0 0})$ & Female $(\mathbf{n}=\mathbf{2 0 0})$ & P value \\
\hline Age $\left(\right.$ years), Mean $\pm S D^{*}$ & $63.91 \pm 11.9$ & $59.96 \pm 11.2$ & 0.001 \\
BMI $\left(\mathrm{kg} / \mathrm{m}^{2}\right), N(\%)$ & & & 0.001 \\
Underweight & $20(10.0)$ & $37(18.5)$ & \\
Normal & $104(52.0)$ & $118(59.0)$ & \\
Overweight & $68(34.0)$ & $36(18.0)$ & \\
Obese & $8(4.0)$ & $9(4.5)$ & $<0.001$ \\
Smoking Status $N(\%)$ & & & \\
Never & $53(26.5)$ & $113(56.5)$ & \\
Former & $74(37.0)$ & $44(22.0)$ & $<0.001$ \\
Current & $73(36.5)$ & $43(21.5)$ & \\
Packs per year** & & & \\
$<30$ & $53(26.5)$ & $113(56.5)$ & \\
$\geq 30$ & $147(73.5)$ & $87(43.5)$ & \\
\hline
\end{tabular}

*Standard Deviation

**cigarettes

\subsection{Frequency of Potential Risk Factors between Males and Females}

The distributions of potential risk factors for developing osteoporosis were presented as positive responses (Yes). Practically, males reported more frequently alcohol consumption $(32.5 \%$ vs. $6.5 \%, \mathrm{p}<0.001)$ than females and smoking status $(75.5 \%$ vs. $43.0 \%, \mathrm{p}<0.001)$, respectively. Males were also reported bone's break after a minor fall, as an adult $(63.0 \%)$ in comparison to females $(49.0 \%), \mathrm{p}=0.005$. However, females were reported more frequent thyroid disease $(37.0 \%$ vs. $14.5 \%, \mathrm{p}<0.001)$, and fearing of falling $(29.0 \%$ vs. $20.0 \%), p=0.036$ than males. No other significant differences among genders were found regarding risk factors such as parents' history, rheumatoid arthritis, less activity and taking medications - (Table 2).

Table 2. Frequency of potential risk factors with respect to gender

\begin{tabular}{llll}
\hline Risk factors for Osteoporosis & Male $\boldsymbol{n}(\%)$ & Female $\boldsymbol{n}(\%)$ & P value \\
\hline 1. Parent's history for osteoporosis & $105(52.5)$ & $108(54.0)$ & 0.764 \\
2. Parents - "dowager's hump & $61(30.5)$ & $58(29.0)$ & 0.743 \\
3. $\geq 40$ years & $194(97.0)$ & $199(99.5)$ & 0.122 \\
4. Fracture -adult & $126(63.0)$ & $98(49.0)$ & 0.005 \\
5. Frequency or fear - falling due frail & $40(20.0)$ & $58(29.0)$ & 0.036 \\
6. $\geq 40$-loss 3cm & $72(36.0)$ & $89(44.5)$ & 0.083 \\
7. Low BMI & $26(13.0)$ & $40(20.0)$ & 0.059 \\
8. Taking Drugs for disease $>3$ months & $68(34.0)$ & $75(37.5)$ & 0.465 \\
9. Rheumatoid arthritis & $56(28.0)$ & $70(35.0)$ & 0.132 \\
10. Diagnosis - Thyroid or Diabetes & $29(14.5)$ & $74(37.0)$ & $<0.001$ \\
11. (Female) - Menopause $<45$ & - & $71(35.5)$ & - \\
12. (Female) - Frequency menstruation & - & $41(20.5)$ & - \\
13. (Female) - Ovaries removed $<50$ & - & $25(12.5)$ & - \\
14. (Male) - Low Testosterone & $43(21.5)$ & - & $<0.001$ \\
15. Alcohol Consumption & $65(32.5)$ & $13(6.5)$ & $<0.001$ \\
16. Smoking Status & $151(75.5)$ & $86(43.0)$ & 0.637 \\
17. Activity <30 min & $49(24.5)$ & $45(22.5)$ & 0.823 \\
18. Avoiding calcium supplements & $56(28.0)$ & $54(27.0)$ & 0.593 \\
19. Stay Outside <10min - Without taking vitamin D & $56(28.0)$ & $51(25.6)$ & \\
\hline
\end{tabular}

\subsection{Associations between a Number of Risk Factors and Demographic Characteristics}

A number of risk-factors for osteoporosis did not differ between males and females ( $5.99 \pm 2.2$ vs. $6.28 \pm 2.8, \mathrm{p}=0.565)$. Also, a number of risk-factors for osteoporosis did not differ among underweight individuals (6.93 \pm 2.8$)$, normal (6.05 \pm 2.5$)$, overweight $(5.85 \pm 2.1)$ and individuals with obesity $(6.18 \pm 2.8), p=0.162$. We also found no significant differences among non-smokers, former and current smokers $(p=0.282)$. However, significant associations were observed 
among age groups. Specifically, a number of risk-factors for osteoporosis were gradually increased with age $<55$ yrs old

compared to $\geq 68$ yrs $(6.99 \pm 2.4$ vs. $4.95 \pm 2.0, \mathrm{p}<0.001)$, respectively - (Table 3 ).

Table 3. Associations between demographic characteristics and a (M) number of risk factors

\begin{tabular}{|c|c|c|}
\hline Demographic characteristics & Mean \pm SD & P value \\
\hline Gender & & 0.565 \\
\hline Male & $5.99 \pm 2.2$ & \\
\hline Female & $6.28 \pm 2.8$ & \\
\hline Age Groups & & $<0.001$ \\
\hline$<55$ years & $4.95 \pm 2.0$ & \\
\hline $55-67$ years & $6.34 \pm 2.6$ & \\
\hline$\geq 68$ years & $6.99 \pm 2.4$ & \\
\hline BMI $\left(\mathrm{kg} / \mathrm{m}^{2}\right)$ & & 0.162 \\
\hline Underweight & $6.93 \pm 2.8$ & \\
\hline Normal & $6.05 \pm 2.5$ & \\
\hline Overweight & $5.85 \pm 2.1$ & \\
\hline Obese & $6.18 \pm 2.8$ & \\
\hline Smoking Status & & 0.282 \\
\hline Never & $5.88 \pm 2.6$ & \\
\hline Former & $6.25 \pm 2.3$ & \\
\hline Current & $6.37 \pm 2.6$ & \\
\hline Packs per year & & 0.112 \\
\hline$<30$ & $5.88 \pm 2.6$ & \\
\hline$\geq 30$ & $6.31 \pm 2.4$ & \\
\hline
\end{tabular}

\subsection{An OR Comparisons among Demographic Characteristics for a Number of Risk-Factors with Respect to Gender}

Former Female smokers (OR=1.07; 95\%CI: 0.22-1.91, $\mathrm{p}=0.013)$ and current Female smokers $(\mathrm{OR}=1.12 ; 95 \% \mathrm{CI}$ : $0.25-1.99, \mathrm{p}=0.012$ ) were significantly more likely to report an increased number of risk-factors for osteoporosis compared to non-smokers (reference category), while these associations were significant only for current Male smokers (OR=0.85; 95\%CI: 0.10-1.59, $\mathrm{p}=0.027$ ).

As expected, we found significant association with respect to age. In particular, females aged 55-67 yrs old and aged $\geq 68$ yrs old were significantly more likely to report an increased number of risk factors $(\mathrm{OR}=2.24 ; 95 \% \mathrm{CI}$ : 1.45 3.04, $\mathrm{p}<0.001)$ and, $(\mathrm{OR}=3.05 ; 95 \% \mathrm{CI}: 2.15-3.94, \mathrm{p}<0.001)$, respectively, compared to reference category. However, males aged 55-67 yrs old and aged $\geq 68$ yrs were less likely to report an increased number of factors related to osteoporosis $(\mathrm{OR}=0.49 ; \quad 95 \% \mathrm{CI}:-0.27-1.26, \quad \mathrm{p}<0.001) \quad$ and, $\quad(\mathrm{OR}=1.44$; 95\% $\mathrm{CI}: \quad 0.68-2.20, \mathrm{p}<0.001)$ respectively, compared to reference category.

We also found a decreased likelihood for Males to report a number of risk factors with respect to BMI. Particularly, participants with normal $(\mathrm{OR}=-1.41 ; 95 \% \mathrm{CI}:-2.42,-0.40$, $\mathrm{p}=0.006)$, overweight $\quad(\mathrm{OR}=-1.84 ; 95 \% \mathrm{CI}:-2.88,-0.80$, $\mathrm{p}=0.001)$ and obese BMI $(\mathrm{OR}=-1.87 ; 95 \% \mathrm{CI}:-3.54,-0.20$, $\mathrm{p}=0.029$ ) were significantly less likely to report an increased number of risk factors for osteoporosis compared to reference category, suggesting that a higher BMI or obesity is protective factor for developing osteoporosis. However, these associations were not significant for female gender - (Table 4).

Table 4. OR comparisons in participants' characteristics toward a number of risk-factors for Osteoporosis according to gender.

\begin{tabular}{|c|c|c|c|c|}
\hline Participants' characteristics & Females & & Males & \\
\hline & OR $(95 \% \mathrm{CI})$ & $P$ value & $\mathrm{OR}(95 \% \mathrm{CI})$ & $P$ value \\
\hline \multicolumn{5}{|l|}{ Age Groups } \\
\hline$<55$ years & Ref.* & & Ref. & \\
\hline $55-67$ years & $2.24(1.45,3.04)$ & $<0.001$ & $0.49(-0.27,1.26)$ & $<0.001$ \\
\hline$\geq 68$ years & $3.05(2.15,3.94)$ & $<0.001$ & $1.44(0.68,2.20)$ & $<0.001$ \\
\hline \multicolumn{5}{|l|}{ BMI $\left(\mathrm{kg} / \mathrm{m}^{2}\right)$} \\
\hline Underweight & Ref. & & Ref. & \\
\hline Normal & $-0.78(-1.68,0.12)$ & 0.089 & $-1.41(-2.42,-0.40)$ & 0.006 \\
\hline Overweight & $-0.98(-2.12,0.16)$ & 0.091 & $-1.84(-2.88,-0.80)$ & 0.001 \\
\hline Obese & $-0.24(-2.01,1.53)$ & 0.790 & $-1.87(-3.54,-0.20)$ & 0.029 \\
\hline \multicolumn{5}{|l|}{ Smoking Status } \\
\hline Never & Ref. & & Ref. & \\
\hline Former & $1.07(0.22,1.91)$ & 0.013 & $-0.12(-0.84,0.60)$ & 0.751 \\
\hline Current & $1.12(0.25,1.99)$ & 0.012 & $0.85(0.10,1.59)$ & 0.027 \\
\hline
\end{tabular}

*Reference category 


\section{Discussion}

In this pre-screening test for risk-factors related to osteoporosis we found that current smokers had a greater likelihood of presenting an increased number of risk-factors, despite the fact that smoking status did not differ among smokers and non-smokers. Also, a greater BMI was protective factor for developing osteoporosis. Finally, both, males and females were more likely to report an increased number of risk factors as age increased.

The main finding of this study was that both; female and male current smokers were more likely to report a number of risk-factors suggesting that increasing the risk for osteoporosis development. In agreement with our findings, a previous meta-analysis survey based on hip fracture studies reported that smokers were almost once more likely in risk factor than non-smokers both in case-control $(\mathrm{OR}=1.33)$ and prospective studies $(\mathrm{OR}=1.63)-[14]$. These findings were also similar to another meta-analysis showing that smoking was associated with an increased risk of any fracture compared to non-smokers [15]. Moreover, hip fractures among smokers and non-smokers in accordance with age have been suggested that there were similar odds ratios of hip fracture between smokers and non-smokers at the age of $50 \mathrm{yrs}$. However, the ratios were increased for smokers by an estimated $17 \%$ in patients aged $>60$ years old [16].

We also found that a likelihood of reporting number of risk-factors was decreased as BMI increased suggesting that greater BMI is a protective factor for osteoporosis development. In comparison to our results, data of metaanalysis focused on BMI evaluated that a lower BMI was a significant risk factor for future fracture independently of age and gender [17]. In our study, these associations were significant only for males. Additionally, obesity was a protective factor due to the increased synthesis of estrogen from adipose tissue in postmenopausal females [18]. Moreover, results of cross- sectional study showed that females with lower BMI were at increased risk of osteoporosis and it could be appropriate to maintain a normal weight [19].

Interestingly, both males and females were more likely to report an increased number of risk factors as age increased. In agreement with our results, numerous studies have been demonstrated that osteoporosis is an age-related disorder that affects the bones as people get older [20, 21]. Moreover, the risk for osteoporosis is greater for females after the age of 50 years old (usually occurs between the ages of 45 and 55) according to the International Osteoporosis Foundation due to being post menopause, as a consequence broken bones, because of hormonal changes during menopause that could lead to rapid loss bone mass [22, 23]. Furthermore, evidence has shown that osteoporosis is also a serious health issue for male as age increased. Specifically, during males' lifetime, at least 1 in 5 men over age 50 will suffer from an osteoporotic fracture that is increased to 1 in 3 over 60 years [24], but it was also found that males were more prospective to die than females within a year after breaking a hip depending on problems related to the break [25].

\section{Study Limitations}

Though the study provides reliable findings, it has certain limitations as well bone mineral density (BMD) was not measured as the most common method of Dual-energy X-ray absorptiometry (DXA). In addition, the questionnaire data was based on self-reports and thus, could lead to incorrect results. It is however a wide-reaching screening tests supplying useful and comparative outcomes.

\section{Conclusion}

According to our data analysis, we concluded that smoking is an important risk factor for developing osteoporosis suggesting that smokers were presented with an increased number of risk-factors. Also, the presence of obesity has a central role in development of osteoporosis. Finally, our data indicates that smoking be required to taking into consideration in screening programs in primary care population and thus, health care professionals in order to manage the osteoporosis disease have to focus on "change behavior" of individuals in Primary care.

\section{References}

[1] International Osteoporosis Foundation. OSTEOPOROSIS \& MUSKULOSKELETAL DISORDERS- WHAT IS OSTEOPOROSIS? [Assessed; Dec 5, 2014]. Available from: http://www.iofbonehealth.org/what-is-osteoporosis

[2] International Osteoporosis Foundation. OSTEOPOROSIS \& MUSKULOSKELETAL DISORDERS- WHAT IS OSTEOPOROSIS?- Epidemiology; [Assessed; Dec 5, 2014]. Available from: http://www.iofbonehealth.org/epidemiology

[3] International Osteoporosis Foundation. DATA \& PUBLICATIONS - Facts and Statistics; [Assessed; Dec 5, 2014]. Available from: http://www.iofbonehealth.org/factsstatistics

[4] Lane JM, Serota AC, Raphael B: Osteoporosis: Differences and Similarities in Male and Female Patients. Orthop Clin North Am 2006; 37 (4):4601-609.

[5] Tuck SP, Datta HK. Osteoporosis in the aging male: treatment options. Clin Interv Aging 2007; 2(4):521-36.

[6] Harrison RA, Siminoski K, Vethanayagam D, Mayumdar SR. Osteoporosis-Related Kyphosis and Impairments in Pulmonary Function: A Systematic Review. J Bone Mine Res, 2007; 22(3):447-457.

[7] Curtis JR, Arora T, Donaldson M, Alarcon GS, Callahan LF, Moreland LW, SL Bridges Jr, Mikuls TR. Skeletal Health among African Americans with Recent Onset Rheumatoid Arthritis. Arthritis Rheum 2009; 61(10):1379-1386. 
[8] NATIONAL OSTEOPOROSIS FOUNDATION. Learn about Osteoporosis- Bone Health Basics: Get the Facts- Diseases and Conditions that May Cause Bone Loss; [Assessed; Dec 5, 2014]. Available: http://nof.org/articles/5

[9] World Health Organization (Ed.). Prevention and management of osteoporosis: report of a WHO scientific group. Geneva 2003.

[10] International Osteoporosis Foundation. OSTEOPOROSIS \& MUSKULOSKELETAL DISORDERS-WHO'S AT RISK? [Assessed; Dec 5, 2014]. Available from: http://www.iofbonehealth.org/whos-risk

[11] Eurobarometer S. Attitudes of Europeans towards tobacco 2007; TNS Opinion Social.

[12] International Osteoporosis Foundation. OSTEOPOROSIS AND MUSCULOSKE-LETAL DISORDERS- Osteoporosis Who's at Risk- ONE-MINUTE OSTEOPOROSIS RISK TEST, [Assessed; Aug 22, 2014]. Available from: http://www.iofbonehealth.org/iof-one-minute-osteoporosisrisk-test .

[13] Global Database on Body Mass Index. World Health Organization 2006; Assessed; July 27, 2012.

[14] Ill PO, Alexandre C. Tobacco as risk factor of osteoporosis, myth or reality? Rev Rhum Ed Fr 1993; 60(4):280-286.

[15] Kanis JA, Johnell O, Oden A, Johansson H, De Laet C, Eisman JA, Fujiwara S, Kroger H, McCloskey EV, Mellstrom D, Melton LJ, Pols H, Reeve J, Silman A, Tenenhouse A. Smoking and fracture risk: a meta-analysis. Osteoporos Int 2005; 16(2):55-162.

[16] Law MR, Hackshaw AK. A meta-analysis of cigarette smoking, bone mineral density and risk of hip fracture: recognition of a major effect. $B M J 1997 ; 315(7112): 841-846$.

[17] De Laet C, Kanis JA, Odén A, Johanson H, Johnell O, Delmas P, Eisman JA,Kroger H, Fujiwara S, Garnero P, McCloskey
EV, Mellstrom D, Melton LJ,Meunier PJ, Pols HA, Reeve J, Silman A, Tenenhouse A. Body mass index as a predictor of fracture risk: a meta-analysis. Osteoporos Int 2005; (11):13301338.

[18] Migliaccio S, Greco EA, Fornari R, Donini LM, Lenzi A. Is obesity in women protective against osteoporosis? Diabetes Metab Syndr Obes 2011; 4:273-282.

[19] Asomaning K, Bertone-Johnson ER, Nasca PC, Hooven F, Pekow PS. The association between body mass index and osteoporosis in patients referred for a bone mineral density examination. J Womens Health 2006; 15(9):1028-1034.

[20] Reginster JY, Burlet N. Osteoporosis: A still increasing prevalence. Bone 2006; 38:4-9.

[21] Mac Laughlin EJ, Sleeper RB, Mc Natty D, Raehl CL. Management of age-related osteoporosis and prevention of associated fractures. Ther Clin Risk Manag, 2006; 2(3):281.

[22] NATIONAL OSTEOPOROSIS FOUNDATION. Learn about osteoporosis- Learn about Osteoporosis- Bone Health Basics: Get the Facts- Are You at Risk? [Assessed; Dec 9, 2014]. Available from: http://nof.org/articles/2

[23] Hernlund E, Svedbom A, Ivergard M, Compston J, Cooper C, Stenmark J, McCloskey EV, Jönsson B, Kanis JA. Osteoporosis in the European Union: medical management, epidemiology and economic burden. A report prepared in collaboration with the International Osteoporosis Foundation (IOF) and the European Federation of Pharmaceutical Industry Associations (EFPIA). Arch Osteoporos 2013; 8:136.

[24] Veeresha KL, Gupta P. Osteoporosis: A silent oral health deterrent. Journal of Dentistry and Oral Hygiene 2013;5(6):51-54.

[25] NATIONAL OSTEOPOROSIS FOUNDATION. Learn about Osteoporosis-Detecting Osteoporosis-Just for men [Assessed; Dec 10, 2014]. Available from: http://nof.org/articles/236 